\section{Conservation requires multiple approaches}

SIR - In your News Feature "The tiger's retreat" (Nature 441, 927-930; 2006) you highlight the differing approaches to the protection of India's rapidly diminishing tigers and biodiversity taken by the Wildlife Conservation Society and the Ashoka Trust for Research in Ecology and the Environment (ATREE).

Although strategies might differ, our ultimate goal is the same: to save as much biodiversity (including tigers) as possible.

In some areas, relocation of people out of protected areas, as advocated by Ullas Karanth of the Wildlife Conservation Society, may be the only option. In others, local communities can be effective allies and partners in conservation, as suggested by C. Madhegowda and Nitin Rai of ATREE. A heterogeneous world - and particularly a country such as India - needs multiple complementary approaches (K. S. Bawa, P. H. Raven and R. Seidler Conserv. Biol. 18, 859-860; 2004).

The threats to Indian biodiversity are varied, from invasive species and poaching to infrastructure development. The focus on local communities as major drivers of change, when they are often themselves victims of these pressures, precludes a consideration of the multiple factors degrading protected areas. And the focus on tigers runs the risk of pushing other important components of biodiversity conservation into the background. In addition to the external pressures, we have to worry about governance and policies.

Archaic governance can produce protected areas with no people but little biodiversity. Conversely, good governance can allow biodiversity in protected areas to flourish even with people in or around them. Integrated approaches to conservation, involving the participation of local people, will thus remain indispensable into the foreseeable future.

Kamaljit S. Bawa

Department of Biology, University of

Massachusetts, Boston, Massachusetts 02125, USA, and Ashoka Trust for Research in Ecology and the Environment, 659 5th A Main Road,

Hebbal, Bangalore 560 024, India

\section{Researchers should ensure that their actions are lawful}

SIR - Your News story "From aircraft engineer to FBI suspect" (Nature 442, 232; 2006) highlights academics' naïveté about security issues.

In my opinion, the motives of researchers do matter. Unfortunately, most media portray scientists concerned in these matters, when they come to light, as innocent victims rather than as people who need to be more aware of the risks and who should ensure that their actions are lawful.

In the case you describe in your News story, it is incredible that J. Reece Roth should not have realized that hiring a Chinese graduate student might pose potential security risks. Anyone signing an agreement to receive military government contracts and funding is required by law to sign a waiver stating that the research will not be shared with foreign powers and that all involved must be US citizens. This is standard policy in military-awarded contracts with secret and security-related applications.

Peter Cohen

5507 Englishman Place, Rockville,

Maryland 20852, USA

\section{Wiki and other ways to share learning online}

SIR - As described in your News story

"Online methods share insider tricks"

(Nature 441, 678; 2006), the ability to share detailed technical advances and modifications of existing laboratory protocols is a benefit of web-based publishing. However, there are potential problems with using a wiki-style mechanism for publication of practical procedures. If an original protocol can be edited by any user, without a checking and editing mechanism, then there is the potential for website owners to be seen to promote incorrect and potentially hazardous procedures.

The OpenWetWare site described in your News story is an excellent example of a more 'managed' wiki-style site, but there are other ways of providing dynamic, interactive technical information online. An example that has been operating for several years in the chemistry community is Synthetic pages LLP (www. syntheticpages.org), on whose behalf I am writing. This provides a forum for the dissemination of practical synthetic chemistry procedures online in a different format to a wiki.

Users are encouraged to submit details such as reproducibility, scale of reaction, unsuccessful attempts and modifications to procedures. The submissions are then reviewed by the editors using a 'light-touch' process. Ultimately, more than $95 \%$ are published. Original submissions cannot be directly edited by users, but attributed comments and modifications are encouraged and added at the end of the page. Registered users can hyperlink between pages using the 'comments' facility or within their submission of a new page, so people can see the protocol evolve and see which users have been involved in this process, enabling decisions on how best to use the information.
All the pages on the site can be browsed or searched free of charge and without any form of registration, but users who wish to contribute must register. The site contains pages from all over the world. It has more than 3,600 users and more than 10,000 unique search visits per month.

Although different from a wiki, the format offers a dynamic, interactive style of web-based publishing which could be more valuable to the community because of its managed style, and because the editorial approach enhances the safety and overall value of a submission and subsequent modifications or comments. It is a format that could be extended to many other areas of experimental research, such as biology, engineering, medicine and others.

Stephen Caddick

Department of Chemistry, University College London, 20 Gordon Street, London WC1H OAJ, UK

\section{It's easier to patent plants than to publish research}

SIR - Your timely News story "Is India's 'patent factory' squandering funds?" (Nature 442, 120; 2006) could open a Pandora's box about the prevailing state of affairs in academic research institutions in the developing world. Obtaining a US patent, especially on plant varieties, is an easy alternative to publishing in peer-reviewed journals for high-profile scientists, because money for filing patents is easily available, with no questions asked about the financial viability of the discovery.

The bare truth is that one can pick any vegetatively propagated plant where no prior patent exists, define its identification characteristics and potential benefits for cultivation, pay a fee to the US Patent and Trademark Office and obtain a patent number for subsequent professional rewards - with no demonstrable benefit to biology.

One of the examples cited in your News story, a cow-urine distillate to enhance the activity of antibiotics (US patent 6410059), has been criticized for not having been through scientific scrutiny (see, for example, a report in The Hindu newspaper at www.hinduonnet.com/seta/2002/09/19/ stories/2002091900150300.htm). The claim has never been substantiated by peer-reviewed publications.

This kind of activity, which is widespread, diverts millions of dollars from research into filing patents. The publicly funded scientific institutions concerned should ignore such CV-enhancing practices in favour of published research.

\section{U. C. Lavania}

Central Institute of Medicinal and Aromatic

Plants, Lucknow 226015 , India 